Address for Correspondence: Prof. Patrick M. Honore,

ICU Department, Universitair Ziekenhuis Brussel, Vrije Universiteit Brussel,

Brussels, Belgium.

E-mail: patrick.honore@uzbrussel.be

\begin{tabular}{|l|}
\hline Access this article online \\
Website: \\
www.intern-med.com \\
DOI: \\
10.4103/2224-4018.129495 \\
\hline Quick Response Code: \\
\hline \\
\hline
\end{tabular}

\title{
Multidisciplinarity in emergency and critical care medicine: Specific care is best care!
}

\author{
Patrick M. Honore, Rita Jacobs, Olivier Joannes-Boyau ${ }^{1}$, Elisabeth De Waele, \\ Herbert D. Spapen
}

ICU Department, Universitair Ziekenhuis Brussel, Vrije Universiteit Brussel, Brussels, Belgium, 'ICU Consultant, Haut Leveque University Hospital of Bordeaux, University of Bordeaux 2, Pessac, France

Emergency and critical care medicine have grown into robust self-supporting disciplines with an increasing demand for dedicated highly-skilled physicians. In earlier time, "core" specialists were asked to offer bedside advice in acute care wards. Yet, the "acute" patient often lacks the typical features of a particular pathology but rather displays a subacute, hyperacute or "patchwork"like disease pattern. Moreover, it becomes increasingly difficult for an entirely "organfocused" physician to discern the multitude of potential pitfalls that complicate diagnosis and treatment in an acute setting.

From the above, it is obvious that acute care departments need to be manned with "specialized" acute care physicians to ascertain timely diagnosis and adequate treatment of patients. ${ }^{[1]}$ The list of involved subspecialities is steadily growing and has recently welcomed nephrology, infectious disease, pharmacology, and endocrinology. ${ }^{[2]}$ Of course, no single intensive care or emergency physician is able to remain fully updated on the ever expanding knowledge and practice regarding these subspecialities. ${ }^{[2]}$ Nephrology, for example, has evolved at such pace over the past decades that it needed to be subdivided in dialysis chronic care, kidney transplantation, peritoneal dialysis, and critical care nephrology, each focusing on a specific patient population. ${ }^{[3,4]}$ From its creation almost 20 years ago, ${ }^{[5]}$ critical care nephrology progressively has claimed a key partnership in acute care. Many critical care physicians some of them even without a specific nephrologic background - have become highly qualified international experts in the management of acute kidney injury. Critical care nephrologists can also tackle specific aspects of acute care. One such issue is antimicrobial "fine-tuning" in patients undergoing continuous renal replacement therapy (CRRT). When adapting currently accepted antimicrobial dosing guidelines in CRRT, a majority of patients will be left underdosed. ${ }^{[6]}$ This is unacceptable since it exposes them to inadequate treatment and will induce resistance. ${ }^{[7]}$ Thanks to the outstanding pioneer work of several groups, dose adaptation regimens for antimicrobial drug therapy under CRRT have been created and molded in workable bedside schemes. ${ }^{[8-10]}$ Pertinent clinical applications are the use of a loading dose followed by continuous infusion for administration of time-dependent antibiotics and the use of considerably higher bolus doses of concentrationdependent antibiotics. ${ }^{[7-10]}$ Another example is the recently re-discovered cardio-renal syndrome. Hereupon, the associated viewpoints of critical care nephrologists, cardiologists, and intensive care physicians ${ }^{[1]}$ allowed a better insight in pathophysiology and a more efficient therapeutic approach. ${ }^{[12]}$ Importantly, the coordination of all logistic issues on intermittent and continuous dialysis in an ICU setting ${ }^{[13]}$ enables to generate sufficient financial resources to engage a critical care nephrologist!. ${ }^{[4,14]}$

Subspecialities such as infectiology, pharmacology, and endocrinology also fulfill an indispensable role in daily ICU management. ${ }^{[15]}$ Critical care infectiology focuses (on a $24 / 7$ basis!) on antimicrobial treatment options in typical emergency and ICU conditions (e.g. reanimation, acute 
shock resuscitation, ...). In addition, advice of the infectious diseases specialist can be summoned in various challenging situations that may not or only partly be appreciated by a "general" infectiologist (e.g. prevention and treatment of emerging multi-drug resistant ICU pathogens, ${ }^{[16]}$ antibiotic dosing in patients undergoing complex therapies (e.g. extracorporeal membrane oxygenation, CRRT, burn treatment,...). ${ }^{[10,17]}$

Life-threatening drug-drug interactions have been described in approximately $15 \%$ of ICU patients. ${ }^{[18,19]}$ Also, up to $10 \%$ of ICU admissions are due to drug overdosing or interactions occurring in general wards. ${ }^{[20]}$ As shown recently, ${ }^{[21]}$ the introduction of critical care pharmacology as a "satellite" of its clinical counterpart can dramatically reduce these harmful events and thus improve patient safety and outcome. ${ }^{[21,22]}$

Protracted illness and its inherent metabolic and hormonal changes have paved the way for critical care endocrinology. ${ }^{[23]}$ By unravelling the intricate hormonal pathways and stress interactions that accompany a stay in the ICU, this relatively new subspecialty will probably contribute in lowering morbidity, length of ICU stay and mortality. ${ }^{[24]}$

In conclusion, polyvalence is no longer a valid option in modern critical care. Uniting forces between disciplines represents the only way to cope with the increasing complexity and cumulating know-how in the critical care setting. For this reason, the wide array of upcoming acute care subspecialities must be committed unrestricted growth and development. This will require competent manpower, a well-designed technical framework, and sufficient financial support. The worldwide success of critical care nephrology proves the feasibility of this concept.

It is time to say goodbye to the omniscient intensivist and to welcome constructive multidisciplinarity!

\section{REFERENCES}

1. Ambrose AJ, Lin SY, Chun MB. Cultural competency training requirements in graduate medical education. J Grad Med Educ 2013;5:227-31.

2. Kodali BS, Kim KD, Flanagan H, Ehrenfeld JM, Urman RD. Variability of subspecialty-specific anesthesia-controlled times at two academic institutions. J Med Syst 2014;38:11.

3. Yee J. Newphrologist: The intensive care kidney specialist. Adv Chronic Kidney Dis 2013;20:1-3.

4. Honore PM, Jacobs R, Joannes-Boyau O, De Waele E, Van Gorp V, Boer W, et al. Con: Dialy- and continuous renal replacement (CRRT) trauma during renal replacement therapy: Still under-recognized but on the way to better diagnostic understanding and prevention. Nephrol Dial Transplant 2013;28:2728-33.
5. Bellomo R, Kellum JR, Mehta R, Palevsky PM, Ronco C. The Acute Dialysis Quality Initiative II: The Vicenza Conference. Adv Ren Replace Ther 2002;9:290-3.

6. Joannes-Boyau O, Honore PM, Perez P, Bagshaw SM, Grand H, Canivet JL, et al. High-volume versus standard-volume haemofiltration for septic shock patients with acute kidney injury (IVOIRE study): A multicentre randomized controlled trial. Intensive Care Med 2013;39:1536-45.

7. Honore PM, Jacobs R, Joannes-Boyau O, Boer W, De Waele E, Van Gorp V, et al. Continuous renal replacement therapy allows higher colistin dosing without increasing toxicity. J Transl Intern Med 2013;1:6-8.

8. Honore PM, Jacobs R, Spapen HD. Use of antifungal drugs during continuous hemofiltration therapies. Annu Update Intensive Care Emerg Med 2012;2012:337-44.

9. Jamal JA, Economou CJ, Lipman J, Roberts JA. Improving antibiotic dosing in special situations in the ICU: Burns, renal replacement therapy and extracorporeal membrane oxygenation. Curr Opin Crit Care 2012;18:460-71.

10. Honore PM, Jacobs R, Spapen HD. Antibiotic adsorption on CRRT membranes. Relevance and impact on antibiotic dosing in critically ill patients. Annu Update Intensive Care Emerg Med 2013;33:123-31.

11. Cruz D. Cardiorenal syndromes in critical care: The acute cardiorenal and renocardiac syndromes. Adv Chronic Kidney Dis 2013;20:56-66.

12. House A, Anand I, Bellomo R, Cruz D, Bobek I, Anker S, et al. Definition and classification of Cardio-Renal Syndromes: Workgroup statements from the 7th ADQI Consensus Conference. Nephrol Dial Transplant 2010;25:1416-20.

13. Honore PM, Joannes-Boyau O, Gressens B. CRRT and Logistics: Is there a role for a medical emergency team in CRRT ? Contrib Nephrol 2007;156:354-64.

14. Lui K. Critical care nephrologist: Update in critical care for the nephrologist. Adv Chronic Kidney Dis 2013;20:4-5.

15. Van den Berghe G. Endocrinology in Intensive Care Medicine: New Insights and Therapeutic Consequences. Verh K Acad Geneeskd Belg 2002;64:167-87.

16. Amer MR, Akhras NS, Mahmood WA, Al-Jazairi AS. Antimicrobial Stewardship Program Implementation in a medical intensive care unit in a tertiary hospital in Saudi Arabia. Ann Saudi Med 2013;33:547-54.

17. Honore PM, Jacobs R, Spapen HD. Impact of altered antimicrobial pharmacokinetics on antimicrobial dosing during extracorporeal membrane oxygenation. Annu Update Intensive Care Emerg Med 2014;34 [In Press].

18. Hurford A, Morris AM, Fisman DW, Wu J. Linking antimicrobial prescribing to antimicrobial resistance in ICU before and after an antimicrobial stewardship program. Epidemics 2012;4:203-10.

19. Askani M, Eslami S, Louws M, Wienge PC, Dongelmans DA, Kuiper RA, et al. Frequency and nature of Drug-Drug Interactions in the intensive care unit. Pharmacoepidemiol Drug Saf 2013;22:430-7.

20. Uijtendaal EV, van Hassel LL, Hugenholz GW, Kuck EM, Zwart van Rijkom JE, Cremer OL, et al. Analysis of drug-drug interactions in medical intensive care unit patients. Pharmacotherapy 2014;34:213-9.

21. Preslaski CR, Lat I, Mac Laren R, Poston J. Pharmacist contributions as members of the multidisciplinary ICU team. Chest 2013;144: 1687-95.

22. Edlin R, Round J, Hulme C, McCabe C. Cost-effectiveness analysis and efficient use of the pharmaceutical budget: The key role of the clinical pharmacist. Br J Clin Pharmacol 2010;70:350-5.

23. Sharshar T, Bastuji-Garin S, Polito A, De Jonghe B, Stevens RD, Maxime $\mathrm{V}$, et al. Hormonal status in protracted critical illness and in-hospital mortality. Crit Care 2011;15:R47.

24. Sharshar T, Bastuji-Garin S, De Jonghe B, Stevens RD, Polito A, Maxime V, et al. Hormonal status and ICU-Acquired Paresis in critically ill patients. Intensive Care Med 2010;36:1318-26.

How to cite this article: Honore PM, Jacobs R, Joannes-Boyau O, De Waele E, Spapen HD. Multidisciplinarity in emergency and critical care medicine: Specific care is best care!. J Transl Intern Med 2014;2:1-2. Source of Support: Nil, Conflict of Interest: None declared 